\title{
Exploring the factors of excessive smartphone use by
} undergraduate students

Gbolahan Olasina

Siyanda Kheswa

University of KwaZulu-Natal, South Africa

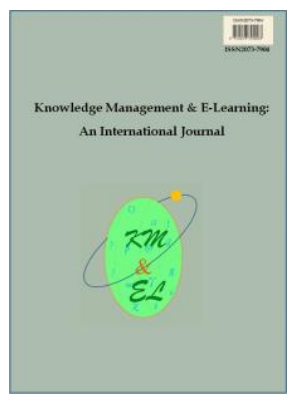

Knowledge Management \& E-Learning: An International Journal (KM\&EL) ISSN 2073-7904

Recommended citation:

Olasina, G., \& Kheswa, S. (2021). Exploring the factors of excessive smartphone use by undergraduate students. Knowledge Management \& ELearning, 13(1), 118-141. https://doi.org/10.34105/j.kmel.2021.13.007 


\title{
Exploring the factors of excessive smartphone use by undergraduate students
}

\author{
Gbolahan Olasina* \\ School of Social Sciences \\ University of KwaZulu-Natal, South Africa \\ E-mail: olasinag@ukzn.ac.za
}

\section{Siyanda Kheswa}

\author{
School of Social Sciences \\ University of KwaZulu-Natal, South Africa \\ E-mail: Kheswas1@ukzn.ac.za
}

*Corresponding author

\begin{abstract}
There is an exponential increase of apprehension in the uptake, affordances and the excessive use of smartphones by multiple categories of users and the impact on the society. The research evaluates excessive use within a user community in a developing country landscape. It is estimated that many young people spend too much time on their phones and the projections suggest even higher numbers with disturbing estimations. The unravelling of contexts surrounding the excessive use of digital devices such as smartphones and the elements that lead to it are mostly unexplored. Consequently, the study illuminated the fundamental mechanisms that influence excessive use of smartphones by learners using perspectives from the Incentive-sensitization Theory (IST) to add scope and breadth. A total of 110 undergraduate students participated in the study. The fundamental results showed that the increase in the volume of activities such as online games, virtual world games and social media was responsible for excessive use. The findings provided an understanding of the relationship between depression-like behaviour and anxiety and shed new light on the influence of excessive use, smartphone stress and depression-related symptoms on students. The study outlined the implications of the results for prevention and regulation.
\end{abstract}

Keywords: Excessive use; Uncontrolled use; Management of information systems; Smartphones; Depression-related symptoms; Students

Biographical notes: Dr Gbolahan Olasina is a senior lecturer, School of Social Sciences, University of KwaZulu-Natal (UKZN), South Africa. He was a postdoctoral research fellow in the Department of Information Science at the University of South Africa, 2014-2016. Gbolahan has taught at several leading universities in Africa in the last sixteen years. He is a C2 NRF-rated researcher. He specializes in the social and cultural effects of technology and his other research interests include research methods in the Social Sciences, Digital Life and educational technology, the evolution of paradigms for Africa, socioinformatics and sustainable development. He has several publications in reputable journals.

Siyanda Kheswa is a lecturer for Information Studies, School of Social Sciences, University of KwaZulu-Natal. On the 3rd of April 2021, he received 
a letter confirming the award of $\mathrm{PhD}$ degree to be conferred on the 11 or 12 May 2021 graduation. His research interests are on the use of the internet for academic purposes, school libraries, information literacy, library user perceptions and adult education.

\section{Introduction}

The potential of smartphones in everyday use and life is translating the way we live. Wang, Xiang, and Fesenmaier (2016) argued that daily life and the use of smartphones are not individually exclusive but unique cases of one another. For instance, the portable media and sensor component-enabled smartphones and associated software applications enable a wireless transmission through connectivity to the Internet. The clinical use of smartphones and their ownership by doctors, nurses, patients and administrators are overbearing though safe and secure use of the tools is essential (Mobasheri et al., 2015). Not only can smartphones afford the saving of lives but even the building of social capital using the lens of apps for creation and communication. For instance, generation-z and millennials are reported to use communication apps driven by smartphones to build and enhance social capital (Mohammed, 2018). Eriani, Lestari, and Rodiyatun (2018) and Guenes, Hottelart, and Reilhac (2018) report the success of the use of smartphone-led apps in catalysing a bonding and a bridging of social capital among the new generation and tech-savvy thus reducing social isolation. Research is scanty on the underlying patterns that frame smartphone use in multiple contexts (Chicioreanu \& Amza, 2018). Improved designs, features, apps, security, media, personalisation and energy management on the smartphones by developers such as Samsung, Apple, Tencent have continued to attract growing numbers of users globally (Fu, 2018; Aggarwal, Choudhary, \& Mehrotra, 2018; Sheta et al., 2018; Chang \& Hwang, 2018). Excessive use covers when individuals use technology tools excessively to cope with daily stressors to regulate their emotions using media-led coping techniques to avoid daily hassles and relieve stress (Kuss et al., 2017; Zhang et al., 2020; Mathew \& Raman, 2020). Accordingly, in the context of the current research, excessive use of the smartphone interchangeably used with keywords such as overuse, frequent use, uncontrolled use and depression related-use based on related literature demarcates any type of behaviour leading to consequences conventionally associated with symptoms such as mood modification, tolerance, salience, withdrawal, insomnia, problematic-use and behavioural-problems (Kuss et al., 2017; Popadić, Pavlović, \& Kuzmanović, 2020; Medero \& Albaladejo, 2020; Wegmann et al., 2020).

There is little evidence of the intercultural and geographic peculiarities in the landscape of smartphone overuse nor are these issues sufficiently studied (De-Sola Gutiérrez et al., 2016). Accordingly, it is fundamental to attract much attention to an improved understanding of the associations in everyday life and context-specific settings in the landscape of smartphone overuse. A primary current focus is to isolate and measure the use of smartphones for their impact on users, determine when uncontrollable use occurs and why and how the new practices and approaches affect learners using the lens of a culturally diverse developing country setting (Olasina, 2018; Olasina, 2020). For example, Rozgonjuk, Saal, and Täht (2018) and Chugh and Ruhi (2018) describe a changing climate of students-led use of smartphone-driven activity related to social media. The authors claim a vital and evolutionary shift that associate with learning and teaching strategies. 
Consequently, a secondary aim of the current study is to investigate similarities with substance addictions in the context of smartphone overuse framed by the process of change in the user when excessive use occurs. The choice of undergraduate students as the focus of the research is based on the fact that excessiveness most frequently occurs during adolescence thus justifying the decision of youths to confirm when overuse of mobile phones begins. The focus of the study is non-formal contexts in day-to-day life. The study seeks to understand, why does excessive use of smartphones occur? To predict and alter the fate of users and help them manage their smartphone use more effectively and enhance our understanding of how to manage overuse. The primary challenge is to improve our knowledge of smartphone overuse and devise interventions to help. Resultantly, the specific questions posed by the research are: What are the factors responsible for the excessive use of smartphones? How do learners perceive smartphone addiction? How do extreme use-related factors relate? Finally, we posed the following alternative hypothesis based on the review of related literature. H1: Loss of control, tolerance, daily life disruption, anxiety and positive anticipation will be positively associated with excessive smartphone usage. After all, it is not clear what factors lead to the overuse of smartphone and how overuse is associated with components such as tolerance, daily life disruption, anxiety, positive anticipation, loss of control, cognitive salience and mood regulation (Herres et al., 2018). The understanding of the relationships among these crucial components remains anecdotal (Morris \& Voon, 2016).

\section{Literature review}

The brief review is framed by related concepts, the overarching purpose of the study, and the adopted theoretical perspectives used to underpin the research.

\subsection{Loss of control}

Panova and Carbonell (2018) and Kwee-Meier, Bützler, and Schlick (2016) ascertain the status of the disorder in the environment of dependency by reviewing research and interviews on smartphone addiction and ubiquitous and networked computing using the lens of loss of control. The authors conclude that problematic use of smartphone should not be considered an addiction. However, the authors report observations of maladaptive, disorder, strains of physical and psychological wellness, phubbing, impulse control issues and problem-based smartphone and networked computing use experiences. The researchers ask for more studies using motivations, compensatory features and gratifications within a socio-cultural perspective to shed new light just as the call for more investigation on the influence of culture and the adoption of social media in the context of employees by Ramawela and Chukwuere (2020). Accordingly, the present research views excessive use within a developing country setting to improve our understanding of the phenomenon.

\subsection{Cognitive salience}

There is a negative side of mobile phone and devices usage (Wolniewicz et al., 2018; Elhai et al., 2017). For instance, Lopez-Fernandez et al. (2018) and Ifeanyi and Chukwuere (2018) identify perception and cognition-stimulated stress, techno-related stress, distress, frustration, impatience based on disconnection with our smartphones, irritation and fear in the landscape of mobile phones. Similarly, Larche, Musielak, and Dixon (2017) use the lens of a mobile phone game Candy Crush to illuminate cognitive 
salience in frustrating outcomes with the gaming platform resulting in continued play to get over a threshold. According to Bae (2017) and Körmendi et al. (2016), user cognition revolves around the smartphone at all times and an (over) reliance on phones (such as even when charging), their immersive features, external and internal components are related to cognitive salience. The role of cognitive salience vis a vis mood modification, relapse, compulsion, negative implications, functional impairment, tolerance, withdrawal, human error and conflict require further study into users of smartphones and related activities (Zhang et al., 2016; Rahman \& Islam, 2020).

\subsection{Mood regulation}

Eisner, Picard, and Hajnóczky (2018) and Somer, Somer, and Jopp (2016) argue that people with less suppressive emotion regulation may be indifferent to the use of smartphones as a result of reinforcement of their management of emotions and conversely, those with high suppressive emotion regulation abilities will be affected by smartphone use. Likewise, Elhai, Hall, \& Erwin (2018) demonstrate that maladaptive emotion regulation strategies frame the association between anxiety severity and problem-led smartphone use. Meanwhile, Elhai et al. (2017) prove that anxiety severity results in a hike in the use of smartphones and establish that anxiety is significantly associated with depression. Extending the previous research would improve our understanding of specific types of mood regulation and anxiety severity using data collected from a developing country environment to contribute to global knowledge in this area. Elhai and Contractor (2018) and Mahapatra (2019) examine mood and selfregulation using the lenses of emotion regulation deficits and ruminative thinking and demographics as predictors of patterns of the use of smartphones. The earlier mentioned authors report heavy and light users of mobile phones and characterise the heavy users with high levels of rumination and emotion regulation strategy and the same user group rate high on all problematic and extended use of mobile phones measurements. The current study unravels new data using a small pool of excessive smartphone users.

\subsection{Tolerance}

Research on the negative consequences shows the issue of misdiagnosis of problematic smartphone use as an addiction but call for more studies to address excessive use problems accurately and effectively (Panova \& Carbonell, 2018). Nikolopoulou and Gialamas (2018) report that adolescent girls experienced higher levels of tolerance and interference with additional activities leading to scenarios such as excessive use of mobile phones to reduce uncomfortable mood, increase in the use hours or when they feel a need for a new smartphone. Agbo-Egwu, Abah, and Anyagh (2017) map users' obsession with students handling of the ubiquity of smartphones in exclusively academic contexts in Nigeria by observing levels of salience, withdrawal, conflict, euphoria and tolerance. The authors find a moderately low level of smartphone addiction while proving a positive correlation between smartphone addiction and dispositional inattentiveness by students in a conventional classroom environment. The existing understanding of the role of tolerance is an assumption that it is limited to addictive symptoms within the landscape of formal education (Horng \& Chao, 2018; Lee, Kim, \& Choi, 2017). The current study gains a better understanding of complete tolerance symptoms in the setting of smartphone overuse in less formal settings to view the disorder agenda. 


\subsection{Daily life disruption}

Research on the concept of daily life disruption shows that fear of missing out drive daily life disruption activities as a result of interruptive notifications in the landscape smartphones for college students (Rozgonjuk et al., 2019). The summary of findings reveals that the symptoms of daily life disruption are led by updated content and actions requiring immediate response of the smartphone user. The frequency of daily disruption symptoms is correlated with detrimental effects on academic work performance of student and hyperactivity symptoms (Harari et al., 2017). Bashar (2017) analyses the role of ICT in protecting citizens from hurtful and abrupt disruptions in the daily life patterns that often result in symptoms of health and economic insecurity in Nigeria. Onyeka et al. (2019) summarise the research on excessive use of smartphone in Nigeria by reporting a need to strike a healthy balance and maintain constant counselling to mitigate overuse among adolescent students and their neglect of key things in life - such as hobbies, school activities, work and face to face relationships. However, little research is conducted in the area of smartphone or computer interruptive notifications and associated psychological constructs concerning their negative effects (Elhai et al., 2021). The lack of studies albeit within the confines of surveys on daily life disruptions in the behaviour of frequent users of smartphones to unfold new insights underpins the current research. The fundamental contribution of the present study is to illuminate how excessive use of the smartphone can be disruptive and detrimental to daily life activities.

\subsection{Anxiety}

Ayandele, Popoola, and Oladiji (2020) investigate the prevalence and association between depression and anxiety-led symptoms among female university students in Nigeria. The findings provide evidence of relationships between depression and anxietyled symptoms and addictive use of smartphones in South-west Nigeria. The authors conclude that university management should outline prevention and strategic interventions to support the wellbeing and health of smartphone users. Afe et al. (2020) explore the pervasiveness of smartphone addiction and the association between the frequency of social media use and psychological morbidity among university students in Nigeria. The researchers conclude that addictive smartphone use is prevalent and correlated with psychological morbidity among male students and underlined the need for interventions reducing prevalence among students. The present study extends our knowledge and understanding of anxiety-led smartphone use in less formal and social settings.

\subsection{Positive anticipation}

Arefin et al. (2018) examine the excessive smartphone usage by the young generation on the educational lives of Bangladeshi students. The research measured the impact of smartphone addiction on academic performance and report positive anticipation. Its components include feeling pleasant/excited and feeling confident, the ability to get rid of stress and 'life will be meaningless without my smartphone' as the core drivers of positive anticipation. El Mawas et al. (2020) report that positive anticipation improved the learning experience and performance of students using a game-based platform. Yayan et al. (2019) explore the relationship between the internet and smartphone addiction of working children in the industry. They find a positive and moderate relationship between positive anticipation and phone addiction. Akpunne and Akinnawo (2018) illuminate research showing Nigerians are top users of smartphones with many maladaptive users. 
The study validated a smartphone addiction scale originated by Kwon et al. (2013) and concluded that the scale is gender-dependent with acceptable psychometric properties relevant to the context of Nigeria.

\subsection{The incentive-sensitisation theory (IST)}

Berridge and Robinson (2016) state that incentive salience takes place by an upsurge in the perception of the value of substance thus making it more attractive and exuding a stronger craving for the user. Resultantly, the scope of the IST continues to extend to various behavioural addictions and related psychopathologies. For instance, the IST has been used to explain drug targets, humans and non-human themes, food, betting, lottery, gambling and sex. The robustness and diverse applicability of the theory make it ideal to underpin the present paper. Also, the theory argues that strong motivation and hedonic pleasure are the drivers of compulsive consumption of substance use and behaviour. Applying the IST to the present study, cues may also contribute to excessive use of smartphones by increasing dependence on the devices. Therefore, the current research employed a small sample of over users of smartphones to understand the underlying factors of over-dependence. Also, the investigation covered the perceptions of constant use, how and when overuse occurs and its negative implications. The relevant core constructs of the IST such as attentional bias, incentive salience, compulsion, desire, pleasure, withdrawal, loss (of reputation, job, home and family) is related directly to the critical questions of the current study to broaden the research. For example, tolerance, incentive salience, anxiety, desire, pleasure, loss of control and positive anticipation were used to underpin critical question to identify the factors responsible for frequent use of smartphones by the students. Finally, the research structure is depicted in Fig. 1 comprising seven independent variables proposing direct relationships with the dependent variable - excessive use of a smartphone; and two moderators.

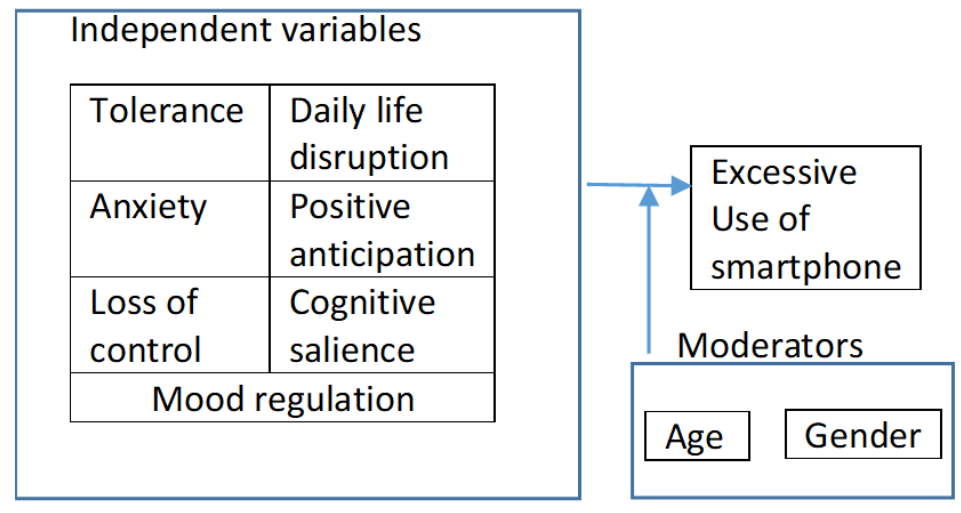

Fig. 1. Research structure

\section{Methods and materials}

\subsection{Respondents}

Initially, a recruitment plan of 500 students using census sampling of the entire undergraduate student population in the Faculty of Communication and Information 
Sciences (FCIS), University of Ilorin, Nigeria was made. The choice was informed by the fact that the students are tech-savvy as the FCIS is the pioneer of open courseware, elearning, m-learning and the tablet-intervention initiative of the institution. After all, ownership of a digital device is compulsory, a prerequisite for registration and LIS modules are educational technology-driven and this category of students address the purpose of the current study. All the students of the Faculty ranging from 100 (year 1) to 400 levels (year 4) were invited to participate in the study. The recruitment strategy involved the excess use metrics that demanded recruits to complete an exploratory questionnaire to guide the selection of participants by identifying a small sample of overusers of smartphones, fundamental to the research. The objectives of the project were introduced to the students during interactive sessions between faculty and researcher and students and between the latter and academic level advisors and at other departmental fora.

Similarly, ethics and related protocols were described and the agenda for confidentiality, anonymity and the elimination of emotional stress for sensitive participants were comprehensively conveyed as per the ethics protocol of the ethics committee at the research site. To put it succinctly, excess use levels were measured based on evidence of poorly controlled preoccupations, behaviour and urges and preference to use smartphones leading to impairment and stress. The excess use metrics involved the exploration of an initial study with questions such as: Do you use a smartphone? Would you be willing to participate (voluntarily)? On the average how many hours do you spend using your smartphone per day? How often do you miss scheduled assignment/work due to the use of a smartphone? Do you experience difficulties concentrating due to use of a smartphone? Additional questions included: Do you suffer physical pain in the hand, wrist or neck and eyes as a result of excessive use of your smartphone? How would you describe your use of a smartphone (basic/standard, average, excessive, addictive)? It was based on the excess use metrics that 112 students who met the needs of the study were selected to participate in the primary research. A hundred and ten (110) students participated and provided signed consent forms. Thirty per cent male and the age range 18-33 years. Sixty per cent belong to years 1 and 2 of study; forty per cent the two final years ( 3 and 4 ). The details of the measures employed in the primary survey are presented next.

\subsection{Measures}

The design of the survey questionnaire was informed by a collection of validated psychometric instruments from several related studies with specific scales recommended with confidence (such as Kwon et al., 2013; Cho \& Lee, 2017; Zhitomirsky-Geffet \& Blau, 2016; Hawi \& Samaha, 2016; Salanova, Llorens, \& Cifre, 2013; Nimrod, 2018; Fried, 2017; Umegaki \& Todo, 2017; Olasina, 2017; Olasina \& Aboyeji, 2020; Csibi et al., 2018; Balakrishnan \& Griffiths, 2017). The survey tool comprised demographics, smartphone usage patterns, smartphone excessive use-like symptoms led by attentional bias and craving and scales for loss of control scale, cognitive salience, tolerance, daily life disruption, anxiety, positive anticipation and mood regulation. Demographics covered age, gender, ethnicity, year of study, state of origin and background information. Content validity was conducted by five experts ( 2 psychiatrists, one expert in Information Systems and two psychometric assessment experts in the Faculty of Education). The content validation procedure ensured the deselection of unrelated questions and a determination of the ultimate collection of questions as approved by Slocumb and Cole (1991). Criterion-related validity of each scale was identified by evaluating the scales and criteria used to validate the instruments and ensure temporal stability in their 
development. Test-retest reliability method was employed to evaluate temporal stability over four weeks using a separate sample of 12 individuals. The scores were consistently $28.1(\mathrm{SD}=2.9)$ and $27.9(\mathrm{SD}=3.1)[t(12)=1.41, p>0.20]$. Pointedly, the overall reliability measurement was 0.81 and the correlation of each item had a coefficient of more than 0.3 by Pearson correlation coefficient as approved by Schober, Boer, and Schwarte (2018). Further details of the measures are found in Appendix I.

\section{Results}

Regression methods adopted involved the removal of correlated components thus retaining a small number of uncorrelated elements to solve the problem of multicollinearity. Also, correlation analysis comprised a deletion of the dataset related to outlier records and discrete variables from skewing the analysis. Table 1 presents the socio-demographic composition and analyses ( $\mathrm{S} / \mathrm{N}$ is the serial number). The framework for the presentation is based on the critical questions of the study.

Table 1

Socio-demographic information, mean scores and SD $(\mathrm{N}=110)$

\begin{tabular}{|c|c|c|c|c|}
\hline $\mathrm{S} / \mathrm{N}$ & Variables & $\mathrm{N}(\%)$ & Mean & SD \\
\hline 1 & $\begin{array}{l}\text { Gender } \\
\text { Male } \\
\text { Female }\end{array}$ & $\begin{array}{l}41(37.3) \\
69(62.7)\end{array}$ & & \\
\hline 2 & $\begin{array}{l}\text { Age } \\
18-25 \\
26-33\end{array}$ & $\begin{array}{l}70 \\
40\end{array}$ & 21.9 & 4.3 \\
\hline 3 & $\begin{array}{l}\text { Economic status/family } \\
\text { Low } \\
\text { Average } \\
\text { High }\end{array}$ & $\begin{array}{l}72(65) \\
33(30) \\
06(5)\end{array}$ & & \\
\hline 4 & $\begin{array}{l}\text { Living (permanent residence) } \\
\text { Self } \\
\text { With a parent } \\
\text { With both parents } \\
\text { With relative } \\
\text { Other }\end{array}$ & $\begin{array}{l}15(13.7) \\
30(27.2) \\
45(40.9) \\
18(16.4) \\
02(1.8)\end{array}$ & & \\
\hline 5 & $\begin{array}{l}\text { Employment } \\
\text { Self-employed } \\
\text { Employed } \\
\text { Not employed } \\
\text { Other }\end{array}$ & $\begin{array}{l}25(22.7) \\
17(15.5) \\
63(57.3) \\
05(4.5)\end{array}$ & & \\
\hline 6 & $\begin{array}{l}\text { Period of use of smartphone } \\
\text { Weekday (in hours) } \\
\text { Weekend (in hours) } \\
\text { Number of days per/week }\end{array}$ & & $\begin{array}{r}10.94 \\
9.81 \\
6.66\end{array}$ & $\begin{array}{l}5.01 \\
6.51 \\
2.90\end{array}$ \\
\hline 7 & $\begin{array}{l}\text { Smartphone activities } \\
\text { Mobile gaming } \\
\text { Social networking } \\
\text { Online videos } \\
\text { Entertainment } \\
\text { Browsing } \\
\text { Others }\end{array}$ & $\begin{array}{l}32(29) \\
20(18.2) \\
11(10) \\
17(15.5) \\
20(18.2) \\
10(9.1)\end{array}$ & & \\
\hline
\end{tabular}


$8 \quad$ Excessive smartphone use-like

symptoms

(self-assessment)

Yes $30(27.3)$

No $75(68.2)$

Not sure $\quad 5(4.5)$

Table 1 reveals the percentages and frequency counts of qualitative variables and the mean (M) and standard deviation (SD) of the quantitative strands. The total number of respondents was 110 . Sixty-nine $(62.7 \%)$ were female and 41 (37.3\%) were male. Seventy of the respondents fall between the 18 - 25 years age group. Seventy-two $(65 \%)$ of the participants come from poor financial backgrounds and the medium is $33(30 \%)$. Further, on the family, $45(40.9 \%)$ come from the background of living with two parents and $30(27.2 \%)$ of respondents belong to one-parent homes. As expected, $63(57.3 \%)$ of respondents are not employed (in any form) while $25(22.7 \%)$ are self-employed. Regarding the self-reported average hours spent using smartphones on weekdays were 10.94 and 9.81 on weekends. The most prominent smartphone activity of the respondents was gaming apps $32(29 \%)$ followed by social networking and browsing $20(18.2 \%)$ and entertainment $17(15.5 \%)$. Only $30(27.3 \%)$ of participants admitted that their use of smartphone was excessive with $57(68.2 \%)$ considering their use of the device as not excessive. There were no significant differences observed based on gender, age group and employment. For instance, gender: $\chi 2(1)=0.14, p=.72$, age group: $t(110)=0.82, p$ $<.81$, employment: $\chi^{2(3)}=0.16, p<.61$. Statistical differences were found in the responses based on the economic status of the family and whether they lived alone, with a parent or both parents. For example, family economic status: $\chi 2(3)=114.11, p<.001$ and residence: $\chi 2(4)=3.54, p<.001$. The critical questions of the study guide the presentation below.

\subsection{What are the factors responsible for the excessive use of smartphones?}

The results of the analysis are presented below.

Table 2

Mobile app usage by frequency

\begin{tabular}{lllc}
\hline S/N & App & Category & Frequency $\%$ \\
\hline 1 & Candy Crush Saga & Gaming & 30.91 \\
2 & Whatsapp & Messaging/Social media/business & 25.36 \\
3 & Facebook & Business/family & 24.01 \\
4 & Opera mini & Mobile browser & 23.23 \\
5 & Instagram & Entertainment & 18.11 \\
6 & Lords Mobile: Battle of the Empires RPG & Gaming - strategy & 11.25 \\
7 & Ma Hauchi & Gaming & 10.21 \\
8 & YouTube & Entertainment/education & 9.67 \\
9 & Banking apps & Business & 9.10 \\
10 & Screen and assess martphone overuse apps & Analytics/usage monitor & 1.1 \\
11 & Text messaging & Messaging/Social & 8.10 \\
12 & Phone calls & Social/Communication & 8.02 \\
13 & iROKOtv & Entertainment & 8.22 \\
14 & 2Go & Social media/interaction/lifestyle & 7.77 \\
15 & Free phone calls, free texting SMS on free number & Lifestyle & 6.14 \\
16 & Take5 Free Slots - Real Vegas Casino & Gaming & 5.18 \\
17 & Tinder & Lifestyle & 4.12 \\
18 & Uber & Travel & 3.24 \\
\hline
\end{tabular}


The analysis of the self-reported usage of smartphones in Table 2 shows that the following categories such as gaming, messaging, business/family, mobile browser, and entertainment apps are the most popular and frequently used accounting for total usage of smartphones. Table 3 presents the smartphone use pattern where SA - Strongly Agree, A - Agree, U - Undecided, D - Disagree and SD - Strongly Disagree.

Table 3

Smartphone use pattern $(\mathrm{N}=110)$

\begin{tabular}{|c|c|c|c|c|c|c|c|}
\hline $\mathrm{S} / \mathrm{N}$ & Item & SA $(\%)$ & $\mathrm{A}(\%)$ & $\mathrm{U}(\%)$ & $\mathrm{D}(\%)$ & $\mathrm{SD}(\%)$ & Mean \\
\hline 1 & $\begin{array}{l}\text { I use my smartphone for social- } \\
\text { driven purposes }\end{array}$ & $70(63.3)$ & $30(27.3)$ & 0 & $8(7.3)$ & $2(1.8)$ & 3.12 \\
\hline 2 & I use my smartphone very often. & $75(68.2)$ & $25(22.7)$ & $3(2.7)$ & $5(4.5)$ & $2(1.8)$ & 4.96 \\
\hline 3 & $\begin{array}{l}\text { My smartphone use experiences } \\
\text { are for information seeking } \\
\text { activities (such as social } \\
\text { networking, IM, online search, } \\
\text { browsing, health, reading news). }\end{array}$ & $20(18.2)$ & $15(13.6)$ & $5(4.5)$ & $35(31.8)$ & $32(29.1)$ & 2.88 \\
\hline 4 & $\begin{array}{l}\text { My fun seeking smartphone } \\
\text { activities include social media, } \\
\text { videos, music, gaming, and e-book }\end{array}$ & $31(28.2)$ & $49(44.5)$ & $2(1.8)$ & $14(12.7)$ & $12(10.9)$ & 2.17 \\
\hline 5 & $\begin{array}{l}\text { I use the smartphone for utility } \\
\text { purposes - snapping photos, } \\
\text { videos, emailing, etc in relation to } \\
\text { efficiency }\end{array}$ & $52(47.3)$ & $22(20)$ & $10(9.1)$ & $20(18.2)$ & $5(4.5)$ & 3.77 \\
\hline 6 & $\begin{array}{l}\text { My use of the smartphone makes it } \\
\text { challenging to give activities and } \\
\text { persons in my life full and } \\
\text { undivided attention }\end{array}$ & $28(25.5)$ & $32(29.1)$ & $9(8.2)$ & $11(10)$ & $30(27.3)$ & 2.18 \\
\hline 7 & $\begin{array}{l}\text { I habitually use the smartphone to } \\
\text { distract from other difficult tasks }\end{array}$ & $2(1.8)$ & $18(16.4)$ & $12(10.9)$ & $46(41.8)$ & $22(20)$ & 3.18 \\
\hline 8 & $\begin{array}{l}\text { The use of the smartphone } \\
\text { squeezes out my personal life, } \\
\text { private contemplation, reflection } \\
\text { or meditation time }\end{array}$ & $17(15.5)$ & $12(10.9)$ & $17(15.5)$ & 34 (30.9) & $30(27.3)$ & 3.43 \\
\hline 9 & $\begin{array}{l}\text { I use the smartphone to distract } \\
\text { myself from unsettling } \\
\text { circumstances, truths and realities } \\
\text { in my moments of solitude }\end{array}$ & $11(10)$ & $24(21.8)$ & $11(10)$ & $30(27.3)$ & $33(30)$ & 2.11 \\
\hline 10 & $\begin{array}{l}\text { The use of the smartphone } \\
\text { mediates my relationship with an } \\
\text { understanding of myself in an } \\
\text { unhealthy way }\end{array}$ & 15 (13.6) & $10(9.1)$ & $10(9.1)$ & $18(16.4)$ & $57(51.8)$ & 3.91 \\
\hline 11 & $\begin{array}{l}\text { A smartphone is a tool that I use to } \\
\text { break away from other persons and } \\
\text { activities that are demanding }\end{array}$ & $10(9.1)$ & $9(8.2)$ & $10(9.1)$ & $20(18.2)$ & $61(55.5)$ & 3.10 \\
\hline 12 & $\begin{array}{l}\text { The use of the smartphone } \\
\text { prevents me from maintaining } \\
\text { healthy patterns and habits thus } \\
\text { disrupting sleep patterns, } \\
\text { interrupting my work and } \\
\text { fragmenting my time and attention }\end{array}$ & $26(23.6)$ & $50(45.5)$ & $10(9.1)$ & $14(12.7)$ & $10(9.1)$ & 2.14 \\
\hline 13 & $\begin{array}{l}\text { I use the smartphone to "burn } \\
\text { time" I could have used to read, } \\
\text { write, converse, interact with } \\
\text { others }\end{array}$ & $10(9.1)$ & $19(17.3)$ & 15 (13.6) & $26(23.6)$ & $32(29.1)$ & 2.11 \\
\hline 14 & $\begin{array}{l}\text { I use my smartphone in a way that } \\
\text { evolves demands on the device }\end{array}$ & $20(18.2)$ & $45(40.9)$ & $8(7.3)$ & 15 (13.6) & $22(20)$ & 3.97 \\
\hline 15 & $\begin{array}{l}\text { I normally keep my smartphone } \\
\text { with me inside the bathroom, } \\
\text { kitchen and odd places }\end{array}$ & $17(15.5)$ & $43(39.1)$ & 0 & $21(19.1)$ & $29(26.4)$ & 2.65 \\
\hline
\end{tabular}


16 I use over 5GB of data per month on my smartphone

17 I often use an earpiece in my smartphone use experiences

18 I often use my smartphone at night

19 I always worry when I visit places where I have to switch off (or network jammed) my smartphone or/and it is taken away from me lectures, exam hall, religious house, embassies, etc.

$\begin{array}{lccccc}10(9.1) & 21(19.1) & 18(16.4) & 50(45.5) & 11(10) & 3.15 \\ 69(62.7) & 20(18.1) & 11(10) & 20(18.1) & 10(9) & 3.11 \\ 40(36.4) & 30(27.3) & 5(4.5) & 18(16.4) & 17(15.5) & 2.18 \\ 30(27.3) & 40(36.4) & 5(4.5) & 15(13.6) & 20(18.2) & 2.15\end{array}$

3.05

A brief analysis of data on Table 3 reveals that 70 (63.3\%) strongly agree that the usage of smartphone is led by social purposes with $2(1.8 \%)$ strongly disagreeing. Likewise, $35(31.8 \%)$ of respondents disagree that information seeking is the underlying driver of their activities on smartphones with 20 (18.2\%) in agreement and $5(4.5 \%)$ undecided. Contrastingly, A total of $68(61.8 \%)$ respondents strongly disagree and disagree with the pattern that they habitually use the smartphone to distract from difficult tasks. Further key results show that a combined number of $80(72.7 \%)$ respondents strongly agreed and agreed that fun-seeking is at the top of their smartphone use agenda with $2(1.8 \%)$ undecided and $12(10.9 \%)$ strongly disagreeing. Similarly, $30(27.3 \%)$ strongly disagree that the use of the smartphone makes it challenging to focus activities and persons undivided attention and $28(25.5 \%)$ and $32(29.1 \%)$ strongly agree and agree with the statement with $9(8.2 \%)$ undecided. Also, $61(55.5 \%)$ of the respondents strongly disagree with a pattern of the use of smartphones to avoiding other persons and demanding activities with $10(9.1 \%)$ in strong agreement and $10(9.1 \%)$ undecided. Also, a combined $76(69.1 \%)$ of participants strongly agree and agree that their smartphone use experience frames their unhealthy sleep life patterns and fragmentation of their time and attention. An integrated 'strongly agree' and 'agree' number of 60 (54.6\%) respondents stand by keeping their smartphones on them for use in the bathroom, kitchen and other odd places with 29 (26.4) in sharp disagreement. Finally, there is evidence that the use of the earpiece is a noticeable feature in the smartphone use patterns $(62.7 \%$ strongly agreed and $18.1 \%$ agreed). The full details are available in Table 3.

Table 4 shows the results of the regression analysis where smartphone use is the dependent variable. Highly correlated variables were removed to retain a smaller collection of uncorrelated elements to solve the problem of multicollinearity. Accordingly, the following components were removed - desire, pleasure, attention bias, anger, obsession and compulsion.

Consider that the analyses involved revision by repeating the analysis after removing some additional factors such as tolerance and daily life disruption to monitor any changes in the negative regression coefficients. Resultantly, no changes were demonstrated despite the repeat conduct of the analysis. Pointedly, the significant factors that associate with excessive use-related (attentional bias/craving) symptoms of the smartphone are daily life disruption, feeling anxious, positive anticipation and loss of control (motivations, compensatory features, gratifications). The following hypothesis was posited: (H1) Loss of control, tolerance, daily life disruption, anxiety and positive anticipation will be positively associated with excessive smartphone usage. The results partially support the hypothesis (H1) based on the effect of daily life disruption, feeling anxious, positive anticipation and loss of control on excessive smartphone use except for one component - tolerance. The factor responsible for the greatest amount of variance is daily life disruption. For instance, $\mathrm{F}(7,110)=4.18, p=.01, \Delta \mathrm{R}^{2}=.03$; step $2, \mathrm{~F}(11,109)$ 
$=5.65, p<.001, \Delta \mathrm{R}^{2}=.11$. Accordingly, factors such as cognitive salience, social impairment, withdrawal, inability to control craving, mood regulation, preoccupation, age, gender and level of study are not significantly associated with excessive smartphone use.

Table 4

Multiple regression analysis

\begin{tabular}{|c|c|c|c|c|c|}
\hline Factors of excessive smartphone use & $\beta$ & B & SE B & $\mathrm{t}$ & $\Delta R^{2}$ \\
\hline (Step 1) & & & & & .03 \\
\hline Cognitive salience & .01 & .41 & .22 & .17 & \\
\hline Social impairment & -.11 & -.41 & .34 & -1.61 & \\
\hline Tolerance & -.04 & -.51 & .27 & -.159 & \\
\hline Withdrawal & -.20 & -.41 & .41 & -1.81 & \\
\hline Daily life disruption & -.08 & -7.51 & 2.72 & $-2.82 * *$ & \\
\hline Inability to control craving & .04 & .06 & .37 & .27 & \\
\hline $\begin{array}{l}\text { Mood regulation } \\
\text { (Step 2) }\end{array}$ & .05 & .03 & .23 & 1.11 & \\
\hline $\begin{array}{l}\text { (Step 2) } \\
\text { Preoccupation }\end{array}$ & .01 & .08 & .69 & .18 & .11 \\
\hline Feeling anxious & .14 & 1.71 & .42 & $2.11 *$ & \\
\hline Positive anticipation & .18 & 1.72 & .18 & $2.16^{* *}$ & \\
\hline $\begin{array}{l}\text { Loss of control } \\
\text { (Step 3) }\end{array}$ & .16 & 1.62 & .16 & $2.98 * * *$ & \\
\hline Age & .01 & .04 & .78 & .77 & \\
\hline Gender & -.11 & .58 & .35 & 1.14 & \\
\hline Level of study & .08 & .33 & .25 & -1.12 & \\
\hline
\end{tabular}

Note. $* p<.05, * * p<.01, * * * p<.001$

\subsection{How do the factors relate to one another?}

The second research question covered the details of the complex relationships among the factors related to excessive use (attentional bias/craving) and associated symptoms. Table 5 below presents the results.

The normality of variables was ensured by conducting Shapiro-Wilk and Kolmogorov-Smirnov tests by using the mean and standard deviation of the sample to compare data to a normal distribution with a value of .09 indicating normality. Also, all variables were measured at the continuous level. In short, social impairment is negatively correlated with cognitive salience. Withdrawal is not associated with overuse of the smartphone $(p>.05)$ and withdrawal has a negative correlation with cognitive salience $(r$ $=-.25, p<.01)$. In other words, inhibitive cognitive control produces withdrawal from smartphone use. There is an inverse correlation between withdrawal and social impairment indicating that smartphone over users' withdrawal issues risk difficulties of social impairment $(r=-.15, p<.01)$. There is no statistically significant correlation between withdrawal and tolerance $(p>.05)$. Daily life routine disruption is negatively oriented toward the excessive use of a smartphone $(r=-.27, p<.01)$. In short, the uncertainty surrounding daily routines increases smartphone use. Excessive preoccupation is positively correlated with cognitive salience, social impairment, tolerance and withdrawal $(r=.27, r=.41, r s=.15, p<.05, p s<.01)$. Preoccupation and 
daily life disruption are negatively correlated $(r=-.31, p<.05)$. There is either a negative or positive correlation between anxiety and each of the other variables. For instance, a negative correlation between anxiety and the following social impairment, tolerance, withdrawal behaviours and daily life disruptions $(r=-.32, r=-.13, r=-.11, r$ $=-.14$, ps <.01). Similarly, positive anticipation is positively correlated with overuse of smartphones, tolerance, withdrawal, daily life disruption, inability to control craving and mood regulation $(r s=.19, .24, .30, .31, p s<.01)$. Positive anticipation is negatively correlated with social impairment, inability to control craving and anxiety $(r s=-.16$, $-.24,-.13, p s<.01)$. The full details are available in Table 5.

Table 5

Correlation analysis

\begin{tabular}{|c|c|c|c|c|c|c|c|c|c|c|c|c|c|c|}
\hline Variables & Mean & SD & 1 & 2 & 3 & 4 & 5 & 6 & 7 & 8 & 9 & 10 & 11 & 12 \\
\hline 1. Excessive smartphone use & 30.10 & 9.82 & - & & & & & & & & & & & \\
\hline 2. Cognitive salience & 1.23 & 0.39 & .11 & - & & & & & & & & & & \\
\hline 3. Social impairment & 1.92 & 0.32 & -.06 & $-.32 * *$ & - & & & & & & & & & \\
\hline 4. Tolerance & 2.22 & 0.38 & $.23 * *$ & $.47 * *$ & $.11 * *$ & - & & & & & & & & \\
\hline 5. Withdrawal & 1.41 & 0.19 & .02 & $-.25 * *$ & $-.15 * *$ & -.05 & - & & & & & & & \\
\hline 6. Daily life disruption & 2.12 & 0.27 & $-.27 * *$ & $.12 *$ & $.17 *$ & -.06 & -.01 & - & & & & & & \\
\hline 7. Inability to control craving & 1.06 & 0.18 & -.04 & .08 & .09 & .07 & $-.28 * *$ & $.51 * *$ & - & & & & & \\
\hline 8. Mood regulation & 1.76 & 0.35 & .02 & $.21 * *$ & .11 & $.22 * *$ & $.25^{* *}$ & $-.14 * *$ & $.30 * *$ & - & & & & \\
\hline 9. Preoccupation & 1.55 & 0.23 & -.06 & $.27 * *$ & $.41 * *$ & $.15^{*}$ & $.15^{*}$ & $-.31 *$ & $.54 * *$ & $.21 * *$ & - & & & \\
\hline 10. Feeling anxious (anxiety) & 2.14 & 0.31 & $.62 * *$ & $.24 * *$ & $-.32 * *$ & $-.13 * *$ & $-.11 * *$ & $-.15 * *$ & $.18^{* *}$ & $.12 *$ & $.14 *$ & - & & \\
\hline 11. Positive anticipation & 2.14 & 0.31 & $.25 * *$ & .11 & $-.16 * *$ & $.19 * *$ & $.24 * *$ & $.30^{* *}$ & $-.24 * *$ & $.31 * *$ & .04 & $-.13 * *$ & - & \\
\hline 12. Loss of control & 2.63 & 0.33 & $.71 * *$ & $.12 *$ & $.38 * *$ & .02 & $.18^{* *}$ & $.13 *$ & $.19 * *$ & $.28 * *$ & $.25 * *$ & .00 & .14 & - \\
\hline
\end{tabular}

\section{Discussion}

There is a high penetration index of mobile telephony globally. Despite the odds of poor electricity to charge handset batteries, old phones, lack of airtime, network and SIM card related problems and other environmental factors there continues to be an explosion in the adoption. Also, the application and the use of smartphones by multiple categories of user groups soars in the developing world and Nigeria in particular as affordability and technical infrastructure improve. Existing smartphone literature outlines contextual issues of problematic smartphone use, addiction, bullying, suicide, security, privacy and related social, excessive use, abuse, cultural and literacy effects of smartphone use with little or no differentiation (Wyche \& Steinfield, 2016; Elhai et al., 2017). By extension, He, Turel, and Bechara (2017) find evidence of both similarity and dissimilarity between social networking sites addiction and substance and gambling addiction. The former, regarding alterations to brain anatomy just as the same study report shows contrast to anterior impairment and underlines brain morphological differences between the range of addictions.

Consequently, the respondents equated excessive use or overuse of smartphones with a perception of addiction and did not want to be associated with that negative phenomenon. It was more comfortable for the respondents to admit devastation of sleeping patterns, withdrawal behaviour than accepting smartphone overuse associated with drug addiction (Elias, Hendlin, \& Ling, 2018; Marks et al., 2018). The implication is that smartphone overuse tends to connote a negative aura that respondents want to distant 
themselves from despite various metrics to the contrary. Also, it implies that constant smartphone users interpret a nonpathological behaviour as perhaps pathological thereby distancing themselves from admitting uncontrollable use or believing themselves not to be regular users.

More importantly, the findings from the current study underline that overuse is not technological but is caused by anxiety, attention-related problems and associated human and social issues and not smartphone technology (Olasina, 2019a). Likewise, the results of the present study reveal that economic status and family/cultural backgrounds mediate the fundamental predictors of smartphone overuse. Toker and Baturay (2016) and Kumcagiz and Gündüz (2016) corroborate the findings of the current study by revealing that socio-economic status and family backgrounds increase gaming and by extension, smartphone addiction. Contrastingly, Muller, Skurtveit, and Clausen (2016) report that elements of poor quality of family life and backgrounds are not associated with addiction specific behaviour of substance users. The current study illuminates only non-technology-based factors to frequent use and the analysis finds no similarities with the practice of substance abusers. The core findings show smartphone overuse is led by specific gaming, messaging, business/family, mobile browser and entertainment situations and contexts. In short, in many ways, frequent use of these apps may result in compulsive smartphone use and powerlessness in the management of such uncontrollable urge. The implication is that the outlined apps could be used for multiple services since they are the focus of users in ways to improve experiences, contextualise excessive use better for more positive ends and affordances. In other words, overuse of the smartphone is not necessarily a disorder on its own. In the flip side is a need to monitor possible risks and the psychological implications of the enormous time spent using screen media on smartphones and a lack of impulse control issues evident in the use of the apps above (Olasina, 2019b).

The critical range of stimuli for excessive smartphone use includes daily life disturbance, anxiety, positive anticipation and loss of control. The fundamental component is daily life disruption $\left.\mathrm{F}(11,109)=5.65, p<.001, \Delta \mathrm{R}^{2}=.11\right]$. Tolerance could not be confirmed as a factor in excessive smartphone use. The reasons might be attributed to the adaptation with the smartphone and the feeling of the students towards the phenomenon. By extension, against all expectations, the following factors of cognitive salience, social impairment, withdrawal, inability to control craving, mood regulation, preoccupation, age, gender and level of study are not positively associated with excessive smartphone use. The implication is that daily life disruption (of personal, familial, and/or formal and informal learning activities) overbearingly drives excessive smartphone use behaviour. Researchers in the area of negative effects of technology need to understand that the predictor strength between tolerance and excessive smartphone use becomes less strong when attention bias and craving are involved. The overuse is fuelled by a motivation to complete high levels of time-consuming apps (such as gaming and social), the need to attain positive anticipation, reduce anxiety or the goal to address perceived social isolation.

The second critical question of the study was to illustrate how excessive smartphone use occurs. The core of the findings in this regard evidenced the complex interrelationships, strengths, direction and weaknesses between the variables of interest. The criticality of the results is for the determination of prevalence and linkages among the variables and to project events based on current thinking and data. In practical terms, the forecasts aim to drive decision making and initiate change-related activities in the excessive use of smartphones and improve user experiences of the device. For instance, tolerance triggers cognitive salience whereas the latter is not well understood in existing 
literature (Brondolo et al., 2016; Fisher, 2016). Cognitive control and salience exert a strong influence on social impairment, thus implying that uncontrollable smartphone users' perception and cognition drive disassociation and a lack of relations with other people in their non-smartphone-based environments. The fact that inability to control craving is positively associated with withdrawal suggests that latter can be managed to make constant smartphone users to cope better without using a smartphone (nomophobia) and to get less irritated even though they crave for their device. For example, Liu et al. (2018) report that loss of control, anxiety and a lack of control of craving lead to mobile phone uses the inability to control the duration of time spent on the devices. Gao et al. (2018) state that individuals are exhibiting symptoms of failure to control mobile phone use a situation which tends to have withdrawal issues alongside.

The results found in the present study resonate well with prior findings in multiple contexts that report a negative correlation between social impairment and cognitive salience; withdrawal and cognitive salience; mood regulation/preoccupation and daily life disruption; preoccupation and everyday life. Also, positive anticipation has a negative correlation with social impairment, inability to control craving and anxiety. For example, the negative correlations imply when excitement that constant use of the smartphone would meet a need or avoid a situation decreases there is an increase in dissociation from relations with others (in a physical sense) as well as increases in anxiety and lack of control of craving and vice versa. The significant results help us analyse and understand relations among the predictors of uncontrollable use of the smartphone by isolating those that relate together, require further close scholarly analysis and advance our knowledge of growing constant smartphone use habits. As illustrations, Yarboi et al. (2017) observed a negative relationship between social environmental factors and cognitive functions in sickle cell patients. Reinecke et al. (2017) state inverse correlations in a study on the relationship between Internet multitasking and psychological impairments with increases in the fear of missing out by respondents just as Yuan et al. (2016) prove a lack of correlation between network properties of social networking and impaired cognitive control in the landscape of old adolescence and Internet gaming.

\section{Conclusion}

The study has implication for our understanding of uncontrollable and frequent use of smartphones. It is due to the fears of possible adverse effects, psychological issues that push the agenda for best practices to evolve on improved user experiences with the devices. The research outlines the core drivers of constant use of smartphones and analyses the relationships among them. In other words, the study provides a screening of excessive smartphone use to evolve an intervention agenda to enhance overuse for more positive results while at the same time improving the experiences for users. For instance, our understanding of the anti-social platform that phones provide for virtual versus real life can be manipulated for more societal good. Our knowledge of the patterns of use is instructive for targeted interventions to manage better cases of uncontrollable use of smartphones. Resultantly, stakeholders can better evaluate and map use patterns for possible links to addiction with more evidence and evolve detection strategies for specific user groups efficiently.

The analyses of the interrelationships among the variables related to smartphone overuse reveal how the treatment of components such as tolerance, daily life disruption, anxiety, positive/negative anticipation, loss of control (motivations, compensatory characteristics and gratifications) can alleviate regular use of the smartphone in ways to enhance meaningful and healthy behaviour in the extended periods using the device. 
Overall, the relationships among the variables seem an alternative predictor of smartphone overuse. Good predictors of excessive use are tolerance, daily life disruption, anxiety, positive anticipation and loss of control. With proper user management of social impairment, cognitive salience, tolerance, inability to control craving and mood regulation, excessive usage habits may be within normal limits (devoid of sleep deprivation and related symptoms). Balancing smartphone use with daily life routines is the best approach. The technology itself does not lead to smartphone overuse unlike drug, substance abuse or related psychological illnesses. Altogether, excessive use of the smartphone is symptomatic of underlying human and social issues and not smartphone addiction in the form of substance abuse.

The main conclusions provide a futuristic map to revise, refine, re-think, verify and influence excessive use of smartphones. It gives a strategical platform for linking prior and current knowledge to future outcomes of device overuse. Also, it formulates and takes actions that would affect the growing explosion of personalised application of smartphones in multiple contexts. The study is limited in many ways. The focus is on student populations that may be misleading of the general population since the former may be driven by impulse and popular culture. Fundamentally, are methodological shortcomings of self-reported survey instrument administered on campus. Active smartphones use sessions and the deployment of use monitoring software could have added texture to the research.

Future studies in meeting with a need to keep over users of smartphones within the eye of scholarly analysis, may compare over users and average users' data and test the anxieties of social interrelations of participants in the landscape of the COVID-19 pandemic using experimental designs. Also, the link between smartphone overuse and substance addiction require evidence just as the connection between smartphones and suicide and smartphone-led disruptions in daily life require more significant intervention.

\section{Author Statement}

The authors declare that they have no conflict of interest.

\section{ORCID}

Gbolahan Olasina (D) https://orcid.org/0000-0002-5732-110X

Siyanda Kheswa (D) https://orcid.org/0000-0002-8486-9875

\section{References}

Afe, T. O., Ogunsemi, O. O., Osalusi, B. S., Adeleye, O. O., \& Ale, A. O. (2020). Age and gender demographics in social media use, smartphone addiction and psychological morbidity among university undergraduates in Southwest Nigeria. Annals of Health Research, 6(1), 22-35.

Agbo-Egwu, A. O., Abah, J. A., \& Anyagh, P. I. (2017). Sustaining attention in a rapidly changing world: A survey of the status among mathematics education students in Nigeria. Benue Journal of Mathematics and Mathematics Education, 2(4), 13-21.

Aggarwal, A., Choudhary, C., \& Mehrotra, D. (2018). Evaluation of smartphones in Indian market using EDAS. Procedia Computer Science, 132, 236-243. 
Akpunne, B. C., \& Akinnawo, O. E. (2018). Validation of smartphone addiction scaleshort version on Nigerian university undergraduates. International Journal of Computer Science and Mobile Computing, 7(11), 136-141.

Arefin, M., Islam, M., Mustafi, M., Afrin, S., \& Islam, N. (2018). Impact of smartphone addiction on academic performance of business students: A case study. Retrieved from https://ssrn.com/abstract=3236301

Ayandele, O., Popoola, O. A., \& Oladiji, T. O. (2020). Addictive use of smartphone, depression and anxiety among female undergraduates in Nigeria: A cross-sectional study. Journal of Health Research, 34(5), 443-453.

Bae, S. M. (2017). Smartphone addiction of adolescents, not a smart choice. Journal of Korean Medical Science, 32(10), 1563-1564.

Balakrishnan, J., \& Griffiths, M. D. (2018). An exploratory study of "selfitis" and the development of the Selfitis behavior scale. International Journal of Mental Health and Addiction, 16(3), 722-736.

Bashar, L. M. (2017). Human security for sustainable development in Nigeria: The role of information and communication technology (ICT). Covenant Journal of Informatics and Communication Technology, 5(2), 29-35.

Berridge, K. C., \& Robinson, T. E. (2016). Liking, wanting, and the incentivesensitization theory of addiction. American Psychologist, 71(8), 670-679.

Brondolo, E., Ng, W., Pierre, K.-L. J., \& Lane, R. (2016). Racism and mental health: Examining the link between racism and depression from a social cognitive perspective. In A. N. Alvarez, C. T. H. Liang, \& H. A. Neville (Eds.), The Cost of Racism for People of Color: Contextualizing Experiences of Discrimination (pp. 109132). Washington, DC: American Psychological Association.

Chang, C. Y., \& Hwang, G. J. (2018). Trends in smartphone-supported medical education: A review of journal publications from 2007 to 2016. Knowledge Management \& ELearning, 10(4), 389-407.

Chicioreanu, T. D., \& Amza, C. G. (2018). Adapting your teaching to accommodate the net generation/Z-generation of learners. eLearning \& Software for Education, 3, 1320.

Cho, K. S., \& Lee, J. M. (2017). Influence of smartphone addiction proneness of young children on problematic behaviors and emotional intelligence: Mediating selfassessment effects of parents using smartphones. Computers in Human Behavior, 66, 303-311.

Chugh, R., \& Ruhi, U. (2018). Social media in higher education: A literature review of Facebook. Education and Information Technologies, 23(2), 605-616.

Csibi, S., Griffiths, M. D., Cook, B., Demetrovics, Z., \& Szabo, A. (2018). The psychometric properties of the smartphone application-based addiction scale (SABAS). International Journal of Mental Health and Addiction, 16(2), 393-403.

De-Sola Gutiérrez, J., Rodríguez de Fonseca, F., \& Rubio, G. (2016). Cell-phone addiction: A review. Frontiers in Psychiatry, 7: 175.

Eisner, V., Picard, M., \& Hajnóczky, G. (2018). Mitochondrial dynamics in adaptive and maladaptive cellular stress responses. Nature Cell Biology, 20(7), 755-765.

El Mawas, N., Tal, I., Moldovan, A. N., Bogusevschi, D., Andrews, J., Muntean, G. M., \& Muntean, C. H. (2020). Investigating the impact of an adventure-based 3D solar system game on primary school learning process. Knowledge Management \& ELearning, 12(2), 165-190.

Elhai, J. D., \& Contractor, A. A. (2018). Examining latent classes of smartphone users: Relations with psychopathology and problematic smartphone use. Computers in Human Behavior, 82, 159-166.

Elhai, J. D., Dvorak, R. D., Levine, J. C., \& Hall, B. J. (2017). Problematic smartphone use: A conceptual overview and systematic review of relations with anxiety and 
depression psychopathology. Journal of Affective Disorders, 207, 251-259.

Elhai, J. D., Hall, B. J., \& Erwin, M. C. (2018). Emotion regulation's relationships with depression, anxiety and stress due to imagined smartphone and social media loss. Psychiatry Research, 261, 28-34.

Elhai, J. D., Rozgonjuk, D., Alghraibeh, A. M., \& Yang, H. (2021). Disrupted daily activities from interruptive smartphone notifications: Relations with depression and anxiety severity and the mediating role of boredom proneness. Social Science Computer Review, 39(1), 20-37.

Elias, J., Hendlin, Y. H., \& Ling, P. M. (2018). Public versus internal conceptions of addiction: An analysis of internal Philip Morris documents. PLoS Medicine, 15(5): e1002562.

Eriani, E., Lestari, D. P., \& Rodiyatun, R. (2018). The roles of headmasters' leadership in preparing professional teachers for generation $\mathrm{Z}$ students. International Colloquium: Opportunities and Challenges on Education Management in 21st Century, 1(1), 1926.

Fisher, S. (2016). Homesickness, cognition and health. London, UK: Routledge.

Fried, E. I. (2017). The 52 symptoms of major depression: Lack of content overlap among seven common depression scales. Journal of Affective Disorders, 208, 191197.

Fu, Q. K. (2018). Impacts of mobile technologies, systems and resources on language learning: A systematic review of selected journal publications from 2007-2016. Knowledge Management \& E-Learning, 10(4), 375-388.

Gao, S., Calhoun, V. D., \& Sui, J. (2018). Machine learning in major depression: From classification to treatment outcome prediction. CNS Neuroscience \& Therapeutics, 24(11), 1037-1052.

Guenes, E. B., Hottelart, K., \& Reilhac, P. (2018). The digital driver of the future-User experience research on generation Z in Germany. In G. Meyer \& S. Beiker (Eds.), Road Vehicle Automation 4 (pp. 57-68). Springer.

Harari, G. M., Müller, S. R., Aung, M. S. H., \& Rentfrow, P. J. (2017). Smartphone sensing methods for studying behavior in everyday life. Current Opinion in Behavioral Sciences, 18, 83-90.

Hawi, N. S., \& Samaha, M. (2016). To excel or not to excel: Strong evidence on the adverse effect of smartphone addiction on academic performance. Computers \& Education, 98, 81-89.

He, Q., Turel, O., \& Bechara, A. (2017). Brain anatomy alterations associated with social networking site (SNS) addiction. Scientific Reports, 7: 45064.

Herres, J., Caporino, N. E., Cummings, C. M., \& Kendall, P. C. (2018). Emotional reactivity to daily events in youth with anxiety disorders. Anxiety, Stress, \& Coping, 31(4), 387-401.

Horng, S. M., \& Chao, C. L. (2018). How risk tolerance constrains perceived risk on smartphone users' risk behavior. In S. Latifi (Ed.), Information Technology - New Generations (pp. 67-72). Springer.

Ifeanyi, I. P., \& Chukwuere, J. E. (2018). The impact of using smartphones on the academic performance of undergraduate students. Knowledge Management \& ELearning, 10(3), 290-308.

Körmendi, A., Brutoczki, Z., Vegh, B. P., \& Szekely, R. (2016). Smartphone use can be addictive? A case report. Journal of Behavioral Addictions, 5(3), 548-552.

Kumcagiz, H., \& Gündüz, Y. (2016). Relationship between psychological well-being and smartphone addiction of university students. International Journal of Higher Education, 5(4), 144-156.

Kuss, D. J., Dunn, T. J., Wölfling, K., Müller, K. W., Hędzelek, M., \& Marcinkowski, J. 
(2017). Excessive Internet use and psychopathology: The role of coping. Clinical Neuropsychiatry: Journal of Treatment Evaluation, 14(1), 73-81.

Kwee-Meier, S. T., Bützler, J. E., \& Schlick, C. (2016). Development and validation of a technology acceptance model for safety-enhancing, wearable locating systems. Behaviour \& Information Technology, 35(5), 394-409.

Kwon, M., Kim, D. J., Cho, H., \& Yang, S. (2013). The smartphone addiction scale: Development and validation of a short version for adolescents. PloS One, 8(12): e83558.

Larche, C. J., Musielak, N., \& Dixon, M. J. (2017). The candy crush sweet tooth: How 'near-misses' in candy crush increase frustration, and the urge to continue gameplay. Journal of Gambling Studies, 33(2), 599-615.

Lee, H., Kim, J. W., \& Choi, T. Y. (2017). Risk factors for smartphone addiction in Korean adolescents: smartphone use patterns. Journal of Korean Medical Science, 32(10), 1674-1679.

Liu, X.-X., Dang, J.-P., Tang, Y., \& Hu, Y.-Q. (2018). Influence of social support on the impact of mobile phone dependence on anxiety levels of Chinese adolescents. Biomedical Research, 29(1), 65-70.

Lopez-Fernandez, O., Männikkö, N., Kääriäinen, M., Griffiths, M. D., \& Kuss, D. J. (2018). Mobile gaming and problematic smartphone use: A comparative study between Belgium and Finland. Journal of Behavioral Addictions, 7(1), 88-99.

Mahapatra, S. (2019). Smartphone addiction and associated consequences: Role of loneliness and self-regulation. Behaviour \& Information Technology, 38(8), 833-844.

Marks, L. R., Munigala, S., Warren, D. K., Liang, S. Y., Schwarz, E. S., \& Durkin, M. J. (2018). Addiction medicine consultations reduce readmission rates for patients with serious infections from opioid use disorder. Clinical Infectious Diseases, 68(11), 1935-1937.

Mathew, P., \& Raman, K. (2020). Impact of problematic internet use on the self-esteem of adolescents in the selected school, Kerala, India. Archives of Psychiatric Nursing, 34(3), 122-128.

Medero, G. S., \& Albaladejo, G. P. (2020). The use of a wiki to boost open and collaborative learning in a Spanish university. Knowledge Management \& E-Learning, 12(1), 1-17.

Mobasheri, M. H., King, D., Johnston, M., Gautama, S., Purkayastha, S., \& Darzi, A. (2015). The ownership and clinical use of smartphones by doctors and nurses in the UK: A multicentre survey study. BMJ Innovations, 1(5), 174-181.

Mohammed, A. B. (2018). Selling smartphones to generation Z: Understanding factors influencing the purchasing intention of smartphone. International Journal of Applied Engineering Research, 13(6), 3220-3227.

Morris, L. S., \& Voon, V. (2016). Dimensionality of cognitions in behavioural addiction. Current Behavioral Neuroscience Reports, 3(1), 49-57.

Muller, A. E., Skurtveit, S., \& Clausen, T. (2016). Many correlates of poor quality of life among substance users entering treatment are not addiction-specific. Health and Quality of Life Outcomes, 14: 39.

Nikolopoulou, K., \& Gialamas, V. (2018). Mobile phone dependence: Secondary school pupils' attitudes. Education and Information Technologies, 23(6), 2821-2839.

Nimrod, G. (2018). Technostress: Measuring a new threat to well-being in later life. Aging \& Mental Health, 22(8), 1086-1093. doi: 10.1080/13607863.2017.1334037

Olasina, G. (2017). An evaluation of educational values of YouTube videos for academic writing. The African Journal of Information Systems, 9(4), 232-261.

Olasina, G. (2018). Factors of best practices of e-learning among undergraduate students. Knowledge Management \& E-Learning, 10(3), 265-289.

Olasina, G. (2019a). Human and social factors affecting the decision of students to accept 
e-learning. Interactive Learning Environments, 27(3), 363-376.

Olasina, G. (2019b). The impact of YouTube videos on academic writing performance. The International Journal of Learning: Annual Review, 26(1), 17-30.

Olasina, G. (2020). Cultural expression using digital media by students. Journal of African Media Studies, 12(3), 351-364.

Olasina, G., \& Aboyeji, A. O. (2020). Understanding e-learning acceptance by students: Relationships among dominant human and social components. Ubiquitous Learning: An International Journal, 13(3), 1-24. doi: 10.18848/1835-9795/CGP/v13i03/1-24

Onyeka, E. B., Chisom, E. O., Nchedochukwu, E. C., Uchechukwu, E. A., \& Ikechukwu, E. B. (2019). Exploring pattern of smartphone addiction among students in secondary schools in lagos state and its counselling. International Journal of English Literature and Social Sciences (IJELS), 4(5), 1488-1493.

Panova, T., \& Carbonell, X. (2018). Is smartphone addiction really an addiction? Journal of Behavioral Addictions, 7(2), 252-259.

Popadić, D., Pavlović, Z., \& Kuzmanović, D. (2020). Intensive and excessive Internet use: Different predictors operating among adolescents. Psihologija, 53(3), 273-290.

Rahman, M. H., \& Islam, M. S. (2020). Building a model for digital content management in agricultural university libraries in Bangladesh. Knowledge Management \& ELearning, 12(3), 359-379.

Ramawela, S., \& Chukwuere, J. E. (2020). Cultural influence on the adoption of social media platforms by employees. Knowledge Management \& E-Learning, 12(3), 344358.

Reinecke, L., Aufenanger, S., Beutel, M. E., Dreier, M., Quiring, O., Stark, B., Wölfling, K., \& Müller, K. W. (2017). Digital stress over the life span: The effects of communication load and internet multitasking on perceived stress and psychological health impairments in a German probability sample. Media Psychology, 20(1), 90115 .

Rozgonjuk, D., Elhai, J. D., Ryan, T., \& Scott, G. G. (2019). Fear of missing out is associated with disrupted activities from receiving smartphone notifications and surface learning in college students. Computers \& Education, 140: 103590.

Rozgonjuk, D., Saal, K., \& Täht, K. (2018). Problematic smartphone use, deep and surface approaches to learning, and social media use in lectures. International Journal of Environmental Research and Public Health, 15(1): 92.

Salanova, M., Llorens, S., \& Cifre, E. (2013). The dark side of technologies: Technostress among users of information and communication technologies. International Journal of Psychology, 48(3), 422-436.

Schober, P., Boer, C., \& Schwarte, L. A. (2018). Correlation coefficients: Appropriate use and interpretation. Anesthesia \& Analgesia, 126(5), 1763-1768.

Sheta, A., Mohsen, A., Sheta, B., \& Hassan, M. (2018). Improved localization for android smartphones based on integration of raw GNSS measurements and IMU sensors. In Proceedings of the International Conference on Computer and Applications (ICCA) (pp. 297-302). IEEE.

Slocumb, E. M., \& Cole, F. L. (1991). A practical approach to content validation. Applied Nursing Research, 4(4), 192-195.

Somer, E., Somer, L., \& Jopp, D. S. (2016). Parallel lives: A phenomenological study of the lived experience of maladaptive daydreaming. Journal of Trauma \& Dissociation, 17(5), 561-576.

Toker, S., \& Baturay, M. H. (2016). Antecedents and consequences of game addiction. Computers in Human Behavior, 55(Part B), 668-679.

Umegaki, Y., \& Todo, N. (2017). Psychometric properties of the Japanese CES-D, SDS, and PHQ-9 depression scales in university students. Psychological Assessment, 29(3), 
354-359.

Wang, D., Xiang, Z., \& Fesenmaier, D. R. (2016). Smartphone use in everyday life and travel. Journal of Travel Research, 55(1), 52-63.

Wegmann, E., Müller, S. M., Turel, O., \& Brand, M. (2020). Interactions of impulsivity, general executive functions, and specific inhibitory control explain symptoms of social-networks-use disorder: An experimental study. Scientific Reports, 10: 3866.

Wolniewicz, C. A., Tiamiyu, M. F., Weeks, J. W., \& Elhai, J. D. (2018). Problematic smartphone use and relations with negative affect, fear of missing out, and fear of negative and positive evaluation. Psychiatry Research, 262, 618-623.

Wyche, S., \& Steinfield, C. (2016). Why don't farmers use cell phones to access market prices? Technology affordances and barriers to market information services adoption in rural Kenya. Information Technology for Development, 22(2), 320-333.

Yarboi, J., Compas, B. E., Brody, G. H., White, D., Rees Patterson, J., Ziara, K., \& King, A. (2017). Association of social-environmental factors with cognitive function in children with sickle cell disease. Child Neuropsychology, 23(3), 343-360.

Yayan, E. H., Dağ, Y. S., Düken, M. E., \& Ulutaş, A. (2019). Investigation of relationship between smartphone addiction and internet addiction in working children in industry. Journal of Human Sciences, 16(1), 143-154.

Yuan, K., Qin, W., Yu, D., Bi, Y., Xing, L., Jin, C., \& Tian, J. (2016). Core brain networks interactions and cognitive control in internet gaming disorder individuals in late adolescence/early adulthood. Brain Structure and Function, 221(3), 1427-1442.

Zhang, K. Z. K., Chen, C., Zhao, S. J., \& Lee, M. K. O. (2016). Failure to decrease the addictive use of information systems: An empirical investigation of smartphone game addiction. In Proceedings of the PACIS.

Zhang, R., Zou, D., Xie, H., Au, O. T. S., \& Wang, F. L. (2020). A systematic review of research on e-book-based language learning. Knowledge Management \& E-Learning, 12(1), 106-128.

Zhitomirsky-Geffet, M., \& Blau, M. (2016). Cross-generational analysis of predictive factors of addictive behavior in smartphone usage. Computers in Human Behavior, 64, $682-693$. 


\section{Appendix I}

Tolerance:

7. I try cutting my smartphone usage time, but I fail.

8. I use smartphone for a longer time and spend more money than I intended.

9. The motivations behind my increased use of the smartphone include avoiding physical contact with friends/family/people; relive stress/tension; habit; social pressure; distraction; thrill; risk-taking; escape.

10. Using my phone is my priority even when I have crucial things to do.

11. I use smartphone to escape from the loneliness and depression (mood modifications)

12. How much longer have you spent on VSNs than you planned?

13. I find I have been hooking on smartphone use.

14. I have increased attentional bias to the smartphone per week in recent 3 months.

15. I was told more than once that I spent too much time (attentional bias) using the smartphone.

16. I need to spend an increasing amount of time on smartphone to achieve the same satisfaction as before.

Daily life disruption:

17. I will never give up using my smartphone even when my daily life is already greatly affected by it.

18. I make small adjustments to my daily life to allow me to continue without questioning the use of smartphone.

19. I am unable to engage in my daily life routines due to the use of smartphone

20. Sometimes I have difficulty with daily life smartphone use accompanying the onset of illness.

21. I feel the exertion on my ability to engage with tasks of daily life leading to increase dependence on smartphone.

22. There is a pre-conscious, spontaneous impulse accounting for the presence of smartphone disruption.

23. The structure of my daily life is affected by smartphone use.

24. Disruptive practices around are a strong influence.

25. I feel restless and irritable when the smartphone is unavailable.

26. I feel the urge to use the smartphone again right after I stopped using it.

Anxiety:

27. I moderately experience common anxiety disorder-related smartphone use (such as panic, social anxiety, post-traumatic stress).

28. I am with a higher level of attachment anxiety resulting to increased use of smartphone.

29. I am more smartphone immersed because I am often afraid to be left alone and abandoned.

30. I feel anxious even in casual in-person (face to face get together) leading to reliance on smartphone.

31. I am usually at ease when using my smartphone to interact with a member of the other sex.

32. I usually feel comfortable using my smartphone when I'm in a group of people I don't know.

33. I get anxious when I must talk to a teacher/supervisor or a mentor in-person but less so with smartphone-talk.

34. My physical environment often makes me crave and uncomfortable pushing use of smartphone. 
35. I am considerably less shy in smartphone enabled-social interactions than most people.

36. I sometimes feel tense during in-person interactions as opposed to smartphone.

37. I wish I had more confidence outside of my smartphone use zone.

38. I seldom get anxious in multiple contexts without smartphone.

39. Overall, I am an anxious person.

40. I fear I lose control of smartphone use experience.

41. I have a sense of dread when I am not with my smartphone.

Positive anticipation:

42. There is nothing more fun to do than using smartphone.

43. Feeling most liberal while using smartphone.

44. Not being able to use smartphone would be painful.

45. Constantly checking smartphone so as not to miss conversations between other people on social media, etc.

46. I have a feeling of anticipation while waiting for the outcome of smartphone experience.

47. I could anticipate how smartphone use encounters will improve my life.

48. Using smartphone makes me think of reward/social value.

49. I look forward to using smartphone to gain satisfaction, enjoyment and accomplishment.

50. I use my smartphone when I am alone and it feels like I am intimate with it.

51. From when I received a smartphone-gift currently/past (from friend/family), I still feel the emotion and it reminds me of the giver.

52. I use smartphone to feel better.

53. When I satisfy my smartphone craving, I feel less depressed.

54. When I use my smartphone, I feel comforted.

Loss of control:

55. I feel like I have smartphone on my mind all the time.

56. I often feel guilty for a craving to use my smartphone.

57. I find myself preoccupied with using smartphone.

58. When I crave something, I know I won't be able to stop using my smartphone once I start.

59. Being with someone who frequently uses the smartphone usually makes me crave for mine.

60. I fail to control the impulse to use smartphone.

61. I try to spend less time on smartphone, but the efforts were in vain.

62. I find myself engaged on smartphone for longer periods than intended.

63. My life would be joyless without the smartphone.

Cognitive salience:

64. For some years now, I usually want to overuse my smartphone even though I know it (overuse) may be unpleasant.

65. The smartphone dominates my thinking.

66. Having my smartphone in my mind even when I am not using it

67. Spend a great deal of time and energy using and thinking about my smartphone.

68. Feel that using my smartphone is a way of life.

69. Using smartphone in ways that can feel like work.

70. Regularly continue using smartphone even when tired.

71. Think about using smartphone even when involved in other activities.

72. I am energetically aroused using smartphone for extensive periods. 
73. I use smartphone for long periods as it gives me control of things often beyond my control.

74. I do not like any interference when using smartphone.

Mood regulation:

75. In the last three days, I have felt a little more sad than usual in smartphone use experience.

76. Often I feel overpowered by hopelessness and turn to use smartphone.

77. In the past three days, I have been brooding over my failures and find myself spending extended periods on smartphone.

78. When I am feeling negative emotions, I make sure to spend more time using smartphone.

79. When I use smartphone for extended periods, my emotions are overwhelming.

80. Feel frustrated and disappointed and get in a bad mood when I do not use smartphone.

81. Often when in a bad mood and loss of confidence in myself, it leads to the use of smartphone. 